\title{
Spinal Cord Injury Facts and Figures at a Glance
}

https://www.nscisc.uab.edu

February 2011

This is a publication of the National Spinal Cord Injury Statistical Center, Birmingham, Alabama.

Incidence: It is estimated that the annual incidence of spinal cord injury (SCI), not including those who die at the scene of the accident, is approximately 40 cases per million population in the U. S. or approximately 12,000 new cases each year. Since there have not been any incidence studies of SCI in the U.S. since the 1990 's it is not known if incidence has changed in recent years.

Prevalence: The number of people in the United States who are alive in 2010 who have SCI has been estimated to be approximately 265,000 persons, with a range of 232,000 to 316,000 persons. Note: Incidence and prevalence statistics are estimates obtained from several studies. These statistics are not derived from the National SCI Database.

The National Spinal Cord Injury Database has been in existence since 1973 and captures data from an estimated 13\% of new SCI cases in the U.S. Since its inception, 26 federally funded SCI Model Systems have contributed data to the National SCI Database. As of October 2010, the database contained information on 27,553 persons who sustained traumatic spinal cord injuries. All the remaining statistics on this sheet are derived from this database or from collaborative studies conducted by the model systems. Detailed discussions of all topics on this sheet may be found in special issues of the journal Archives of Physical Medicine and Rehabilitation published in November 1999, November 2004, and March 2011.

Age at injury: SCI primarily affects young adults. From 1973 to 1979, the average age at injury was 28.7 years, and most injuries occurred between the ages of 16 and 30 . However, as the median age of the general population of the United States has increased by approximately 9 years since the mid-1970, the average age at injury has also steadily increased over time. Since 2005, the average age at injury is 40.7 years. Other possible reasons for the observed trend toward older age at injury might include changes in either referral patterns to model systems, the locations of model systems, survival rates of older persons at the scene of the accident, or age-specific incidence rates.

Gender: Overall, $80.7 \%$ of spinal cord injuries reported to the national database have occurred among males. Over the history of the database, there has been a slight trend toward a decreasing percentage of males. Prior to $1980,81.8 \%$ of new spinal cord injuries occurred among males.

Race/Ethnicity: A significant trend over time has been observed in the racial/ethnic distribution of persons in the database. Among persons injured between 1973 and 1979, 76.8\% were Caucasian, $14.2 \%$ were African American, and $0.9 \%$ were Asian. However, among those injured since $2005,66.5 \%$ are Caucasian, $26.8 \%$ are African American, and $2.0 \%$ are Asian. Hispanic increased from $5.9 \%$ in 1970 's to $12.5 \%$ in $2000-2004$ and $8.3 \%$ since 2005 . This trend is due in part to trends in the United States general population and also possibly explained by the changing locations of model systems, referral patterns to model systems, or racespecific incidence rates.

Etiology: Since 2005, motor vehicle crashes account for $40.4 \%$ of reported SCI cases. The next most common cause of SCI is falls, followed by acts of violence (primarily gunshot wounds).
The proportion of injuries that are due to sports has decreased over time while the proportion of injuries due to falls has increased. Violence caused $13.3 \%$ of spinal cord injuries prior to 1980 , and peaked between 1990 and 1999 at $24.8 \%$ before declining to only $15.0 \%$ since 2005 .

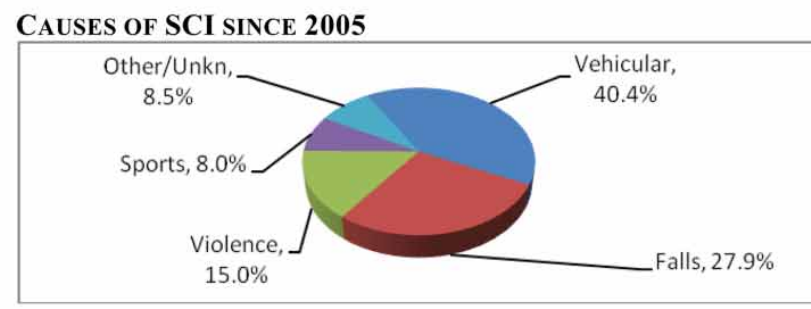

Neurologic level and extent of lesion: Persons with tetraplegia have sustained injuries to one of the eight cervical segments of the spinal cord; those with paraplegia have lesions in the thoracic, lumbar, or sacral regions of the spinal cord. Since 2005, the most frequent neurologic category at discharge of persons reported to the database is incomplete tetraplegia $(39.5 \%)$, followed by complete paraplegia $(22.1 \%)$, incomplete paraplegia $(21.7 \%)$ and complete tetraplegia $(16.3 \%)$. Less than $1 \%$ of persons experienced complete neurologic recovery by hospital discharge. Over the last 15 years, the percentage of persons with incomplete tetraplegia has increased while complete paraplegia and complete tetraplegia have decreased slightly.

Occupational status: More than half $(57.3 \%)$ of those persons with SCI admitted to a model system reported being employed at the time of their injury. At one year after injury, $11.6 \%$ of persons with SCI are employed. By 20 years post-injury, $35.2 \%$ are employed and a similar level of employment is observed through post-injury year 30 .

Residence: Overall, $89.8 \%$ of all persons with SCI who are discharged alive from the system are sent to a private, noninstitutional residence (in most cases their homes before injury). Only $6.2 \%$ are discharged to nursing homes. The remaining are discharged to hospitals, group living situations or other destinations.

Marital status: Considering the youthful age of most persons with SCI, it is not surprising that most $(51.9 \%)$ are single when injured. Among those who were married at the time of injury, as well as those who marry after injury, the likelihood of their marriage remaining intact is slightly lower when compared to the general population. The likelihood of getting married after injury is also reduced.

Length of stay: Overall, median days hospitalized in the acute care unit for those who enter a model system immediately following injury has declined from 24 days between 1973 and 1979 to 12 days since 2005. Substantial downward trends are noted for days in the rehab unit (from 98 to 37 days). Overall, median days hospitalized (during acute care and rehab) were greater for persons with neurologically complete injuries. 
Lifetime costs: The average yearly health care and living expenses and the estimated lifetime costs that are directly attributable to SCI vary greatly according to severity of injury.

\begin{tabular}{|c||c|c||c|c||}
\hline \multirow{2}{*}{\multicolumn{1}{|c||}{ Severity of Injury }} & \multicolumn{2}{c||}{$\begin{array}{c}\text { Average Yearly Expenses } \\
\text { (in 2010 dollars) }\end{array}$} & \multicolumn{2}{c|}{$\begin{array}{c}\text { Estimated Lifetime Costs by } \\
\text { Age At Injury (discounted at 2\%) }\end{array}$} \\
\cline { 2 - 6 } & First Year & Each Subsequent Year & 25 years old & $\mathbf{5 0}$ years old \\
\hline \hline High Tetraplegia (C1-C4) & $\$ 985,774$ & $\$ 171,183$ & $\$ 4,373,912$ & $\$ 2,403,828$ \\
\hline Low Tetraplegia (C5-C8) & $\$ 712,308$ & $\$ 105,013$ & $\$ 3,195,853$ & $\$ 1,965,735$ \\
\hline Paraplegia & $\$ 480,431$ & $\$ 63,643$ & $\$ 2,138,824$ & $\$ 1,403,646$ \\
\hline Incomplete Motor Functional at Any Level & $\$ 321,720$ & $\$ 39,077$ & $\$ 1,461,255$ & $\$ 1,031,394$ \\
\hline
\end{tabular}

Data Source: Economic Impact of SCI published in the journal Topics in Spinal Cord Injury Rehabilitation Volume 16 Number 4 in 2011.

These figures do not include any indirect costs such as losses in wages, fringe benefits and productivity which average $\$ 66,626$ per year in December 2010 dollars, but vary substantially based on education, severity of injury and pre-injury employment history.

Life expectancy is the average remaining years of life for an individual. Life expectancies for persons with SCI continue to increase, but are still somewhat below life expectancies for those with no SCI. Mortality rates are significantly higher during the first year after injury than during subsequent years, particularly for severely injured persons.

\begin{tabular}{|c|c|c|c|c|c|c|c|c|c|c|c|}
\hline & \multicolumn{10}{|c|}{ Life expectancy (years) for post-injury by severity of injury and age at injury } \\
\hline & & \multicolumn{5}{|c|}{ For persons who survive the first 24 hours } & \multicolumn{5}{|c|}{ For persons surviving at least 1 year post-injury } \\
\hline $\begin{array}{c}\text { Age } \\
\text { at } \\
\text { Injury }\end{array}$ & No SCI & $\begin{array}{c}\text { Motor } \\
\text { Functional at } \\
\text { Any Level }\end{array}$ & Para & $\begin{array}{c}\text { Low } \\
\text { Tetra } \\
\text { (C5-C8) } \\
\end{array}$ & $\begin{array}{c}\text { High } \\
\text { Tetra } \\
\text { (C1-C4) }\end{array}$ & $\begin{array}{c}\text { Ventilator } \\
\text { Dependent- } \\
\text { Any Level } \\
\end{array}$ & $\begin{array}{c}\text { Motor } \\
\text { Functional at } \\
\text { Any Level } \\
\end{array}$ & Para & $\begin{array}{c}\text { Low } \\
\text { Tetra } \\
\text { (C5-C8) }\end{array}$ & $\begin{array}{c}\text { High } \\
\text { Tetra } \\
\text { (C1-C4) }\end{array}$ & $\begin{array}{c}\text { Ventilator } \\
\text { Dependent- } \\
\text { Any Level } \\
\end{array}$ \\
\hline 20 & 58.6 & 52.6 & 45.2 & 40.0 & 35.7 & 17.1 & 53.0 & 45.8 & 41.0 & 37.4 & 23.8 \\
\hline 40 & 39.4 & 34.1 & 27.6 & 23.3 & 19.9 & 7.3 & 34.5 & 28.2 & 24.2 & 21.2 & 11.4 \\
\hline 60 & 22.4 & 17.7 & 12.8 & 9.9 & 7.7 & 1.5 & 18.0 & 13.2 & 10.4 & 8.6 & 3.2 \\
\hline
\end{tabular}

Cause of death: In years past, the leading cause of death among persons with SCI was renal failure. Today, however, significant advances in urologic management have resulted in dramatic shifts in the leading causes of death. Persons enrolled in the National SCI Database since its inception in 1973 have now been followed for 35 years after injury. During that time, the causes of death that appear to have the greatest impact on reduced life expectancy for this population are pneumonia and septicemia.

Find additional information in the Annual Report on the NSCISC website: https://www.nscisc.uab.edu/public_content/annual_stat_report.aspx

Presently, there are 14 systems and 7 Form II centers sponsored by the National Institute on Disability and Rehabilitation Research, Office of Special Education and Rehabilitative Services, U.S. Department of Education

U of Alabama-B'ham SCI Model System Birmingham, AL (205) 934-3283

Rocky Mountain Regional SCI System Englewood, CO (303) 789-8220

National Capital Model SCI System

Washington, D.C. (202) 877-1694

Georgia Regional SCI System

Atlanta, GA (404) 352-2020

Midwest Regional SCI Care System

Chicago, IL (312) 238-0764

New England Regional SCI Center

Boston, MA (866) 607-1804

University of Michigan SCI Model System Ann Arbor, MI (734) 763-0971
Northern New Jersey SCI System West Orange, NJ 973-243-3576

Mount Sinai SCI Model System New York, NY (212) 659-9340

Northeast Ohio Regional SCI System Cleveland, $\mathrm{OH}$ (216) 778-7202

Regional SCI System of Delaware Valley Philadelphia, PA (215) 955-6579

$\mathrm{U}$ of Pittsburgh Model System on SCI Pittsburgh, PA (412) 232-7949

Texas Regional SCI System

Houston, TX (713) 799-5023

Northwest Regional SCI System Seattle, WA (206) 616-2183
FORM II CENTERS Collect follow-up data only

Catholic Health Care West - St. Joseph's Hospital Phoenix, AZ (602) 746-9179

Los Amigos Research and Education Institute Downey, CA (562) 401-7541

Santa Clara Valley Medical Center San Jose, CA (408) 885-2383

University of Columbia

Columbia, MO (collected by UAB (205) 934-3283)

NYU Department of Rehabilitation Medicine New York, NY (212) 263-0844

Woodrow Wilson Rehab Center Fishersville, VA (collected by UAB (205) 934-3283)

Virginia Commonwealth University

Richmond, VA (804) 628-0277

This is a publication of the National Spinal Cord Injury Statistical Center, Birmingham, Alabama, which is funded by the National Institute on Disability and Rehabilitation Research (grant \#H133A060039), Office of Special Education and Rehabilitative Services, U.S. Department of Education, Washington, DC. The opinions contained in this publication are those of the grantee and do not necessarily reflect those of the U.S. Department of Education. C2010, Board of Trustees, University of Alabama

The National SCI Statistical Center

1717 6th Avenue South, Room 515, Birmingham, AL 35233-7330;

Voice: (205) 934-3320; TDD: (205) 934-4642; FAX: (205) 934-2709; E-mail: NSCISC@uab.edu 